This item was submitted to Loughborough's Research Repository by the author.

Items in Figshare are protected by copyright, with all rights reserved, unless otherwise indicated.

\title{
A numerical study of intake valve jet flapping in a gasoline direct injection engine
}

PLEASE CITE THE PUBLISHED VERSION

https://doi.org/10.1504/IJPT.2018.10011445

PUBLISHER

(C) Inderscience

VERSION

AM (Accepted Manuscript)

\section{PUBLISHER STATEMENT}

This work is made available according to the conditions of the Creative Commons Attribution-NonCommercialNoDerivatives 4.0 International (CC BY-NC-ND 4.0) licence. Full details of this licence are available at: https://creativecommons.org/licenses/by-nc-nd/4.0/

\section{LICENCE}

CC BY-NC-ND 4.0

\section{REPOSITORY RECORD}

Beavis, Nicholas J., Salah S. Ibrahim, and W. Malalasekera. 2017. "A Numerical Study of Intake Valve Jet Flapping in a Gasoline Direct Injection Engine”. figshare. https://hdl.handle.net/2134/25330. 


\title{
A Numerical Study of Intake Valve Jet Flapping in a Gasoline Direct Injection Engine
}

\author{
*N.J. Beavis, Department of Aeronautical and Automotive Engineering, Loughborough \\ University, Leicestershire, UK, n.beavis@lboro.ac.uk \\ S.S. Ibrahim, Department of Aeronautical and Automotive Engineering, Loughborough \\ University, Leicestershire, UK, s.s.ibrahim@lboro.ac.uk \\ W. Malalasekera, School of Mechanical and Manufacturing Engineering, Loughborough \\ University, Leicestershire, UK, w.malalasekera@lboro.ac.uk
}

\begin{abstract}
This paper presents findings from a numerical study of intake valve jet flapping within a gasoline direct injection (GDI) engine, using a large eddy simulation (LES) turbulence modelling approach. The experimental test case and computational setup, including choice of sub-grid scale (SGS) turbulence model, are presented and discussed. An example cycle where intake valve jet flapping is seen to be prominent is discussed in detail. Intake valve jet flapping was found to be initiated as a consequence of turbulent fluctuations in the intake valve curtains. Cycle-by-cycle variations in valve curtain mass flux and the subsequent jet flapping events are investigated and significant cyclic variability is found. It was observed that when an ensemble-averaging procedure, typically used in LES simulations and experimental PIV data post-processing, is applied, due to the cyclic variability of the variations in valve curtain mass flux, most of the information related to this flow phenomenon is lost.
\end{abstract}

Keywords - CFD, flow, GDI, turbulence, valve jet flapping

\section{1-Introduction}

Investigations into the physical processes occurring within internal combustion engines (ICE) have been of research interest for a number of decades (Lavoie, Heywood \& Keck, 1970; Gosman, Tsui \& Watkins, 1984; Poinsot, 1996; Genzale, Reitz \& Musculus, 2009). One area of continued interest, in particular due to its interaction with the fuel-air mixing and subsequent 
combustion processes, is the in-cylinder flow field. It can be characterised as: three-dimensional, compressible, spatially and temporally varying, fully turbulent, anisotropic, non-homogeneous, has high levels of interaction with solid boundaries and typically contains complex flow phenomena that vary on a cycle-by-cycle basis.

Experimental techniques for characterising the in-cylinder flow field are commonplace in research institutions. However, due to the ICE being a hostile and difficult to access environment, numerical methods remain an integral part of research and development activities. Within three dimensional-computational fluids dynamics (3D-CFD) numerical modelling techniques, traditionally a Reynolds-Averaged Navier-Stokes (RANS) approach to turbulence modelling has been used but this approach has inherent limitations. Time- or Favre-weighted averaging techniques, commonly used in this approach, cause information related to the fluctuating component of the flow field to be lost, losing the ability to investigate phenomenon occurring on a cycle-by-cycle basis and making investigations into unsteady phenomenon like valve jet flapping difficult at best. Recent advances in computing power have seen increased usage of more advanced turbulence modelling approaches, including LES where the large scale eddies are solved directly and only the smaller eddies modelled using a SGS model (Rutland, 2011). This approach allows the investigation into highly transient flow phenomenon occurring on cycle-bycycle basis.

Instability or 'flapping' of a propagating jet is of interest due to its impact on the resultant flow field. Previous experimental (Borée, Maurel \& Bazile, 2002) and numerical (Hasse, Sohm \& Durst, 2009) studies in very simplified engine geometries have been conducted where instability of the propagating jet was observed and suggested as a potential source of the variability seen in the resultant flow structures. Intake valve jet flapping is the sinusoidal flow motion observed in the valve jet penetrating into the cylinder between the two intake valves during the intake stroke and an example of this is shown in Figure 1. This phenomenon has been suggested as a potential source of cycle-to-cycle variability leading to significant differences in the resultant large scale tumbling motion (Hasse, 2016; St Hill, Asadamongkon, Lee, et al., 2000), but in spite of this very little research exists where valve jet flapping has been characterised or attempts made to determine causality. In an experimental context, observations are challenging because of the difficulty of knowing where to position the laser measurement plane within the cylinder a priori, 
and numerical approaches require the use of more computationally expensive turbulence modelling approaches, e.g. LES.

This study has used a detailed 3D-CFD model and LES turbulence modelling approach and applied it to a GDI engine geometry with a view to identifying and investigating intake valve jet flapping. The paper first provides an outline of the experimental engine and then follows with details of the numerical model. Next, the results and discussion section presents an example of intake valve jet flapping and then discusses the findings in relation to causes, cycle-by-cycle variations, and limitations for predicting this phenomenon when using time-averaging techniques. The final section provides the conclusions drawn from this study.

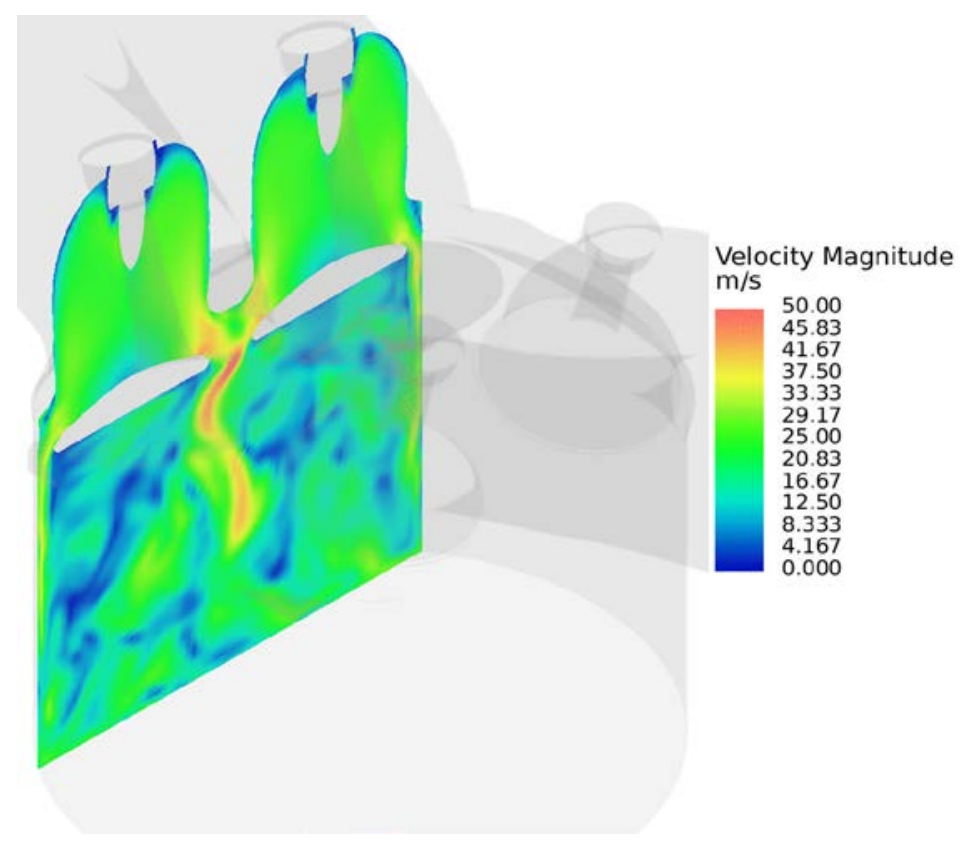

Figure 1 - Velocity magnitude contours providing an example of intake valve jet flapping forming between the two intake valves

\section{2-Experimental Engine}

The experimental engine was a single cylinder four stroke optical research engine based on the combustion chamber of a V8 engine with pent-roof cylinder head, centrally mounted injector and 
four valves per cylinder, representative of a typical commercial GDI engine design. The engine featured a ‘Bowditch’ piston arrangement and fused silica piston crown, cylinder liner and pentroof access window to allow significant optical access to the combustion chamber. The experimental engine is shown in Figure 2 and the configuration is summarised in Table 1. The engine geometry and experimental setup used to obtain the High Speed Digital Particle Image Velocimetry (HSPIV) data used for model validation are described in detail in Jarvis, Justham, Clarke, et al. (2006), Justham, Jarvis, Garner, et al. (2006), Serras-pereira, Aleiferis, Richardson, et al. (2007).

Table 1 - Experimental engine configuration (Jarvis, Justham, Clarke, et al., 2006)

\begin{tabular}{|l|l|}
\hline Bore & $89(\mathrm{~mm})$ \\
\hline Stroke & $90.3(\mathrm{~mm})$ \\
\hline Capacity & $0.562(\mathrm{l})$ \\
\hline Compression ratio & 10.5 nominal \\
\hline Piston bowl shape & Flat \\
\hline Combustion chamber shape & Pent-roof \\
\hline Valves & 2 Intake, 2 Exhaust \\
\hline Intake Valve Opening & $24^{\circ} \mathrm{ATDC}$ \\
\hline Intake Valve Closing & $149^{\circ} \mathrm{ATDC}$ \\
\hline Exhaust Valve Opening & $274^{\circ} \mathrm{ATDC}$ \\
\hline Exhaust Valve Closing & $6^{\circ} \mathrm{ATDC}$ \\
\hline
\end{tabular}




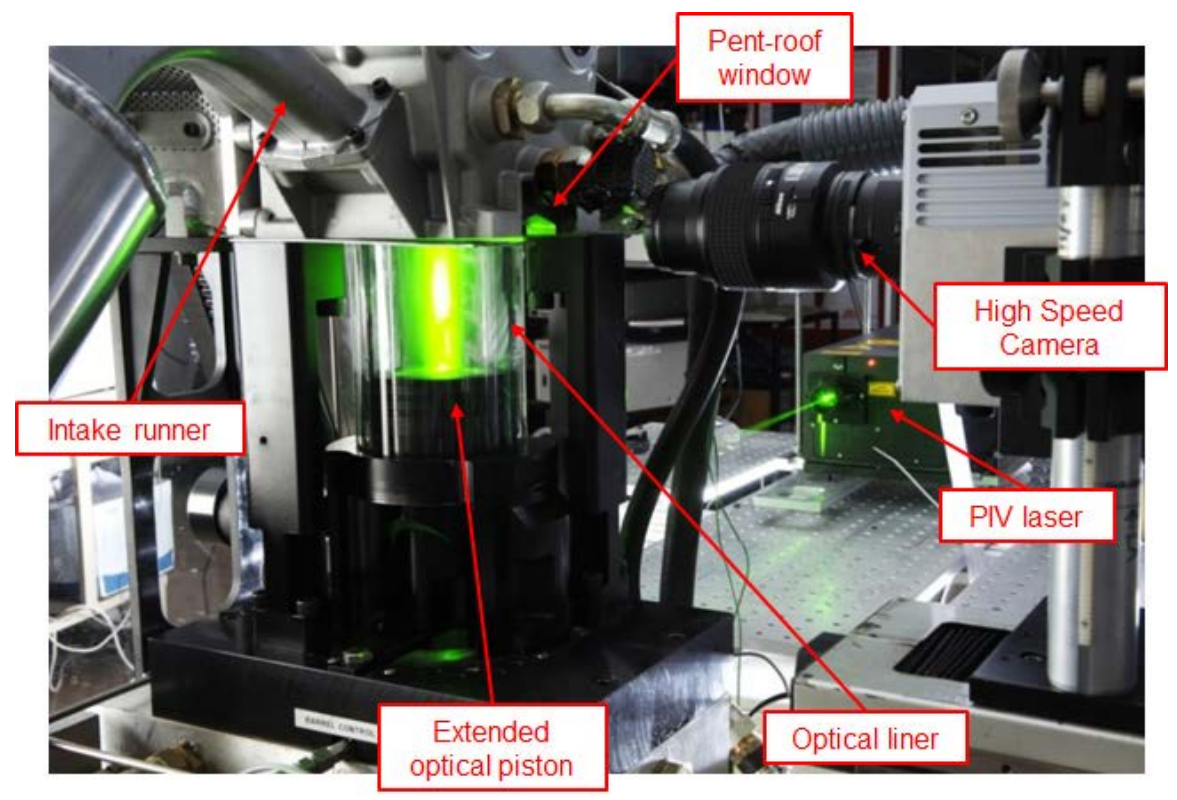

Figure 2 - Single cylinder optical research engine used for model validation

\section{3-Numerical Model}

\section{1-Turbulence Modelling}

Modern CFD codes are based on the governing equations for fluid flow; continuity, momentum and energy equations, which in most codes, including the one used in this research, are solved via the finite volume method.

Due to the random nature of turbulent flows, a statistical approach is taken to define the flow field. The Reynolds Decomposition decomposes the instantaneous velocity component $u_{i}$ into a mean component $\bar{u}_{\imath}$ and a fluctuating component $u_{i}^{\prime}$ (or in an LES context, the filtered and SGS components respectively), as shown by equation (1).

$u_{i}=\overline{u_{\imath}}+u_{i}^{\prime}$

When this decomposition is introduced into the momentum equation, the following equation (2) is formed: 
$\rho \frac{\partial \bar{u}_{i}}{\partial t}+\rho \frac{\partial\left(\bar{u}_{j} \bar{u}_{i}\right)}{\partial x_{j}}=-\frac{\partial \bar{p}}{\partial x_{i}}+\frac{\partial \Gamma_{i j}}{\partial x_{j}}+\rho \frac{\partial \tau_{i j}}{\partial x_{j}}$

Where $\rho$ is the fluid density, $p$ is the pressure and $\Gamma_{i j}$ is the viscous stress tensor. The introduction of the velocity decomposition also introduces a new term $\tau_{i j}$, the Reynolds stresses in a RANS context, or the SGS stresses in an LES context, which forms six additional terms that require modelling to close the Navier-Stokes equations. It is how these six terms are modelled which defines the methodology by which turbulence is modelled.

When taking a LES approach, the SGS stresses are typically resolved by being related to the strain rate tensor $\bar{S}_{i j}$ using a kinematic turbulence viscosity term $v_{T}$, via a Boussinesq or meangradient assumption, as shown in equation (3). The isotropic portion $\tau_{k k}$ is incorporated into the filtered pressure equation, leaving only the anisotropic portion, specifically the turbulence viscosity $v_{T}$, to be modelled.

$\tau_{i j}=-2 v_{T} \bar{S}_{i j}+\frac{1}{3} \delta_{i j} \tau_{k k}$

Where $\delta_{i j}$ is the Kronecker delta.

In this study, the turbulence viscosity term is modelled as proposed by Smagorinsky (1963) based on a local equilibrium assumption such that production and dissipation of SGS turbulence kinetic energy are assumed to be equal and defined by equation (4).

$v_{T}=\left(C_{S} \Delta\right)^{2}|\bar{S}|$

Where $C_{S}$ is the Smagorinsky constant and set to 0.02 in this study based on the findings from Dugue, Gauchet \& Veynante (2006), and $\Delta$ is the filter width defined by equation (4).

$\Delta=\sqrt[3]{V}$

Where $V$ is the cell volume of the computational grid.

In the near-wall region, turbulence was modelled via a law-of-the-wall approach as proposed by Launder \& Spalding (1974), with the exception to the wall heat fluxes which are modelled by the approach proposed by Angelberger, Poinsot \& Delhay (1997). The standard wall functions were formulated for flows with relatively modest variations in temperature across the boundary layer, 
whereas in ICE's the variation can be of the order 2000K. The methodology proposed by Angelberger, Poinsot \& Delhay modifies the temperature wall functions to better account for this affect.

\section{2-Computational Mesh}

The numerical model was developed using CFD code STAR-CD (ver 4.20). The computational domain is shown in Figure 3 and was configured to be a detailed representation of the experimental setup.

The computational meshes for the cylinder, valves and intake and exhaust ports were developed using CD-adapco's dedicated ICE mesh building software called 'es-ice'. The cells are hexahedral throughout and a typical cell size of approximately $0.7-0.8 \mathrm{~mm}^{3}$ was used with the aim of keeping the cell size as uniform as possible. The cylinder periphery included two cylinder wrap layers of $\sim 0.3 \mathrm{~mm}$ and $\sim 0.6 \mathrm{~mm}$ thickness to improve boundary layer predictions.

The computational meshes for the intake plenum and runner and exhaust runner were developed using STAR-CCM+ (ver 8.06). This provided easier control over the variation in cell size throughout the component, allowing either areas of localised refinement or areas of lower cell density, dependent on the expected complexity of the local flow structures, reducing computation time whilst still providing the necessary cell density to capture the local flow structures, as shown by Figure 4. Again the cell type was hexahedral and the variation in cell size throughout the computational domain is summarised in Table 2.

The inclusion of the intake plenum and runner ensure that sufficient time was provided for turbulence to develop prior to the cylinder and the exhaust runner was extended approximately three diameters downstream to prevent recirculating flow features around the flow outlet and any subsequent solver instability.

The final mesh contained approximately 2.2million cells at Bottom Dead Centre (BDC) and the mesh was generally found to provide upward of $80 \%$ turbulence resolution within the cylinder, which is considered adequate for a LES simulation (Fontanesi, Paltrinieri \& D’Adamo, 2013). The model was also validated against experimental HSPIV data at three separate crank angles 
within the intake stroke and at three different tumble cutting planes, and showed reasonable agreement against mean and fluctuating velocity components. For results showing turbulence resolution and comparison of numerical predictions against experimental HSPIV data, the reader is referred to Beavis, Ibrahim \& Malalasekera (2016).

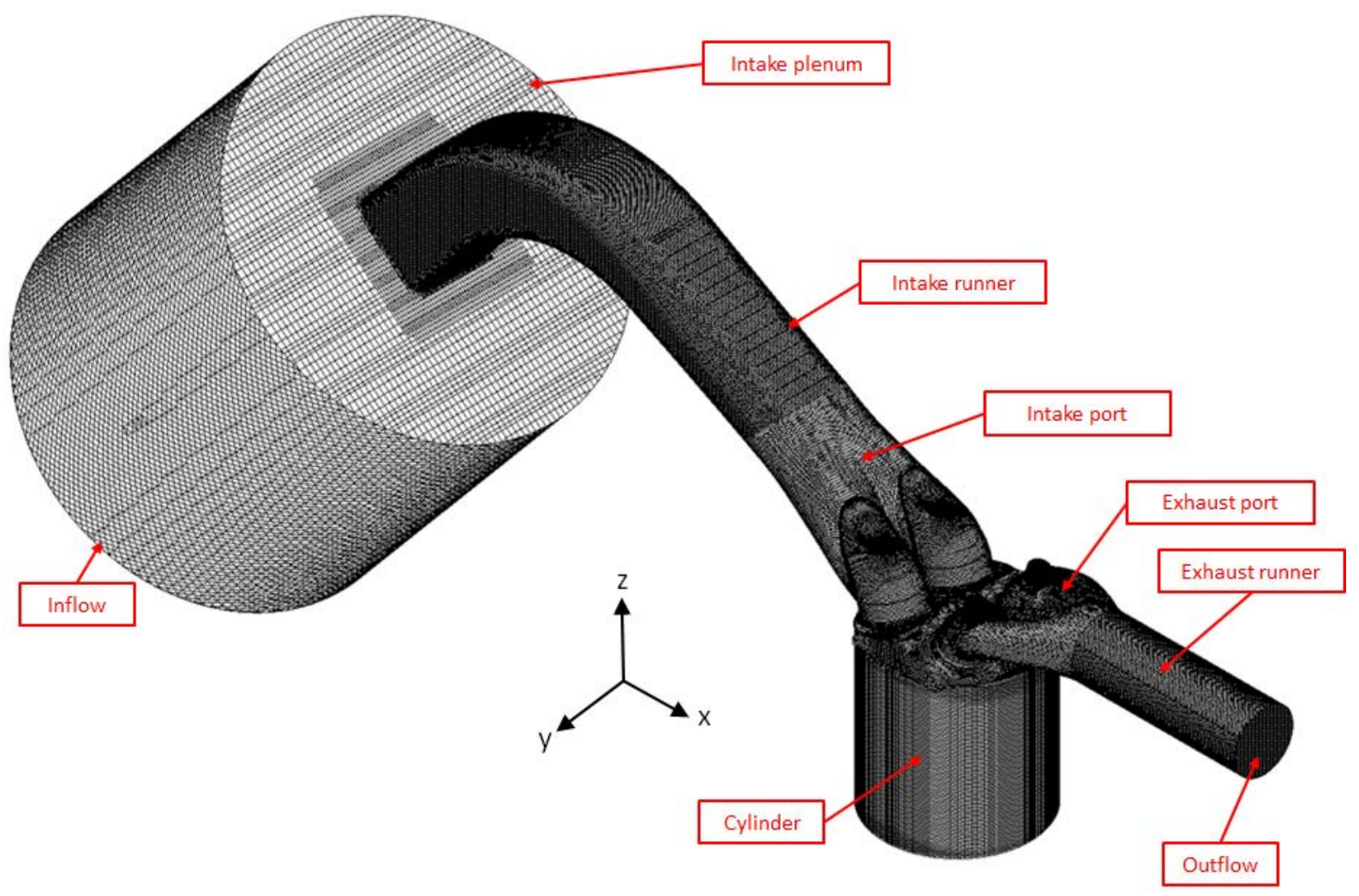

Figure 3 - The computational domain 


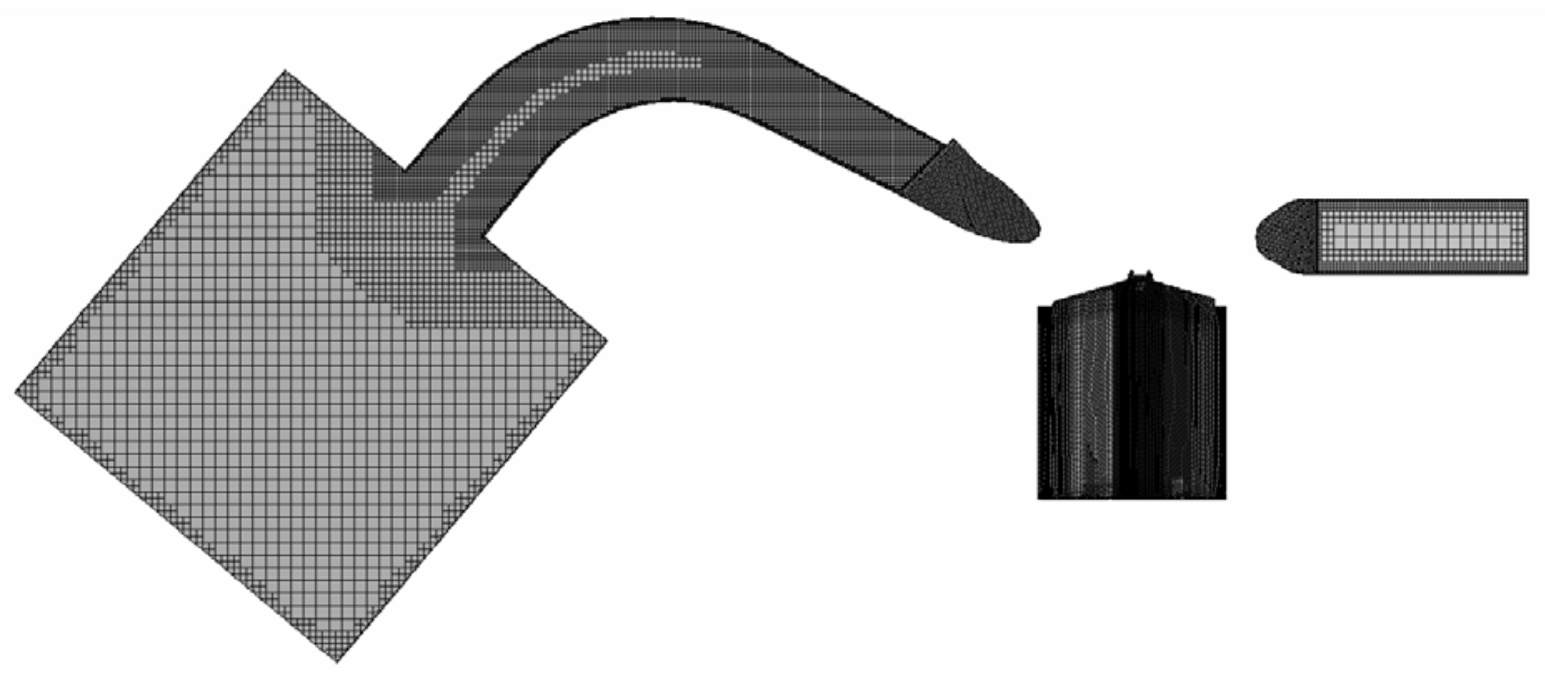

Figure 4 - A section view along the bore centreline showing the computational mesh at $180^{\circ}$ ATDC through the $x-z$ plane

Table 2 - Computational Cell Sizes

\begin{tabular}{|l|l|}
\hline Cylinder Interior & $\sim 0.7-0.8 \mathrm{~mm}^{3}$ \\
\hline Intake port and valve curtain & $\sim 0.7-0.8 \mathrm{~mm}^{3}$ \\
\hline $\begin{array}{l}\text { Exhaust port and valve } \\
\text { curtain }\end{array}$ & $\sim 0.7-0.8 \mathrm{~mm}^{3}$ \\
\hline Intake runner & $0.75-3 \mathrm{~mm}^{3}$ \\
\hline Intake plenum & $1.5-6 \mathrm{~mm}^{3}$ \\
\hline Exhaust runner & $0.75-6 \mathrm{~mm}^{3}$ \\
\hline
\end{tabular}

\section{3-Boundary Conditions}

The inflow at the intake plenum and outflow at the exhaust port outlet were specified as constantpressure and constant-temperature environments. RANS predictions confirmed that the domain was extended sufficiently far upstream and downstream such that a steady pressure boundary was adequate to correctly predict the intake and exhaust system wave dynamics. For results, the reader is referred to Beavis, Ibrahim, Manickam, et al. (2015). A turbulence intensity of 10\% and 
turbulence length scale of $10 \%$ of the hydraulic diameter were imposed at both the inflow and outflow. The numerical boundary conditions are summarised in Table 3.

Table 3 - Numerical boundary conditions

\begin{tabular}{|l|l|}
\hline Engine Speed & $1500(\mathrm{rpm})$ \\
\hline Inflow Pressure & $0.453(\mathrm{bar})$ \\
\hline Inflow Temperature & $301(\mathrm{~K})$ \\
\hline Inflow Turbulence & $\begin{array}{l}\text { Intensity: } 10 \% \\
\text { Length scale: } 0.0048(\mathrm{~m})\end{array}$ \\
\hline Outflow Pressure & 1.023 (bar) \\
\hline Outflow Temperature & 784 (K) \\
\hline Outflow Turbulence & $\begin{array}{l}\text { Intensity: } 10 \% \\
\text { Length scale: } 0.001(\mathrm{~m})\end{array}$ \\
\hline Wall Temperatures & Adiabatic \\
\hline
\end{tabular}

\section{4-Computational Setup}

The simulation was initialised by first running a RANS cycle. This improves solver stability for the first LES cycle by providing more representative initial conditions. The first LES cycle is considered an 'LES initialisation cycle', and is discarded due its dependency on the initial conditions provided by the previous RANS cycle. The simulation is then continued for a further 29 engine cycles which were used for the analysis. The time-step was set at $5.6 \times 10^{-6} \mathrm{~s}$ (equating to approximately 0.05ca/time-step) except around valve opening and closing periods where it was set to $1.1 \times 10^{-6} \mathrm{~s}$ (approximately $0.01 \mathrm{ca}$ /time-step). This provided adequate solution stability, an average Courant-Friedrichs-Lewy (CFL) number of less than one, relative insensitivity to temporal resolution, and equated to a solver time of approximately 79hrs per complete engine cycle when run across 176 CPUs, or 13900 CPU-hrs per cycle. The numerical setup, including temporal and spatial discretisation schemes and residual tolerances, is summarised in Table 4. 
Table 4 - Numerical setup

\begin{tabular}{|l|l|}
\hline Timestep & $\begin{array}{l}\text { General: 5.6x10-6 s } \\
\text { Around valve opening and } \\
\text { closing periods: } 1.1 \times 10^{-6} \mathrm{~s}\end{array}$ \\
\hline $\begin{array}{l}\text { Temporal Discretisation } \\
\text { (pressure-correction) \& } \\
\text { Residual Tolerance }\end{array}$ & $\begin{array}{l}\text { PISO (second-order) } \\
0.0001\end{array}$ \\
\hline $\begin{array}{l}\text { Under Relaxation Factor (for } \\
\text { pressure-correction) }\end{array}$ & $\begin{array}{l}0.3 \\
\text { Momentum: MARS } \\
\text { (second-order) 0.001 } \\
\text { Tifferencing Schemes \& } \\
\text { Residual Tolerance } \\
\text { \& Dissipation: MARS } \\
\text { (second order) 0.001 } \\
\text { Temperature: MARS } \\
\text { (second order) 0.0001 } \\
\text { Density: CD (second order) }\end{array}$ \\
\hline
\end{tabular}

\section{4-Results and Discussion}

In this study, individual cycles were investigated for evidence of intake valve jet flapping. Velocity magnitude contours at $5^{\circ} \mathrm{CA}$ intervals were used in the $\mathrm{y}$-z cutting plane, intersecting through both intake valves. During early observations of the numerical predictions it became apparent that prior to an intake valve jet flapping event, a stronger velocity field was present in one of the intake valve curtains as a consequence of turbulent fluctuations. The difference (valve 1 , at the top of the images, minus valve 2 , at the bottom of the images) in valve curtain flux between the two intake valves was compared to consecutive images of velocity magnitude contours and a relationship found between the temporal variation in valve curtain flux and valve jet flapping. Results from cycle 10 are shown in Figure 5 and Figure 6 and discussed below in more detail below. 
Early in the intake stroke, between $30-70^{\circ}$ ATDC, variations in mass flux past the intake valve curtains are small and this is reflected in a fairly constant jet propagating down the centre of the combustion chamber (Figure 6(a)).

At around $75^{\circ} \mathrm{ATDC}$ a significant variation in valve curtain mass flux occurs between the two intake valves, with a visible weakening of the flow through the left valve curtain (Figure 6(b)).

This imbalance in valve curtain flux causes a momentary strengthening of the valve jet from the right hand valve and a resultant instability in the combined vertical jet, causing it to propagate more diagonally under the left intake valve.

$5^{\circ} \mathrm{CA}$ later at $80^{\circ} \mathrm{ATDC}$, the difference in valve curtain flux has returned to similar values but this oscillation in the relative strength of each valve jet causes the resulting jet to begin to 'flap' in a sinusoidal motion (Figure 6(c)).

A further $5^{\circ} \mathrm{CA}$ later at $85^{\circ} \mathrm{ATDC}$, since the valve curtain flux had stabilised $5^{\circ} \mathrm{CA}$ earlier, any flapping has been dissipated but a weakening of the flow past the left valve prompts the initiation of further valve jet flapping, which is then visible at $90^{\circ}$ ATDC (Figure 6(d) \& Figure 6(e)).

This process continues until approximately $140^{\circ}$ ATDC where any difference in valve curtain flux between the two intake valves is minimal as a consequence of much lower valve jet velocities at large valve lifts. 


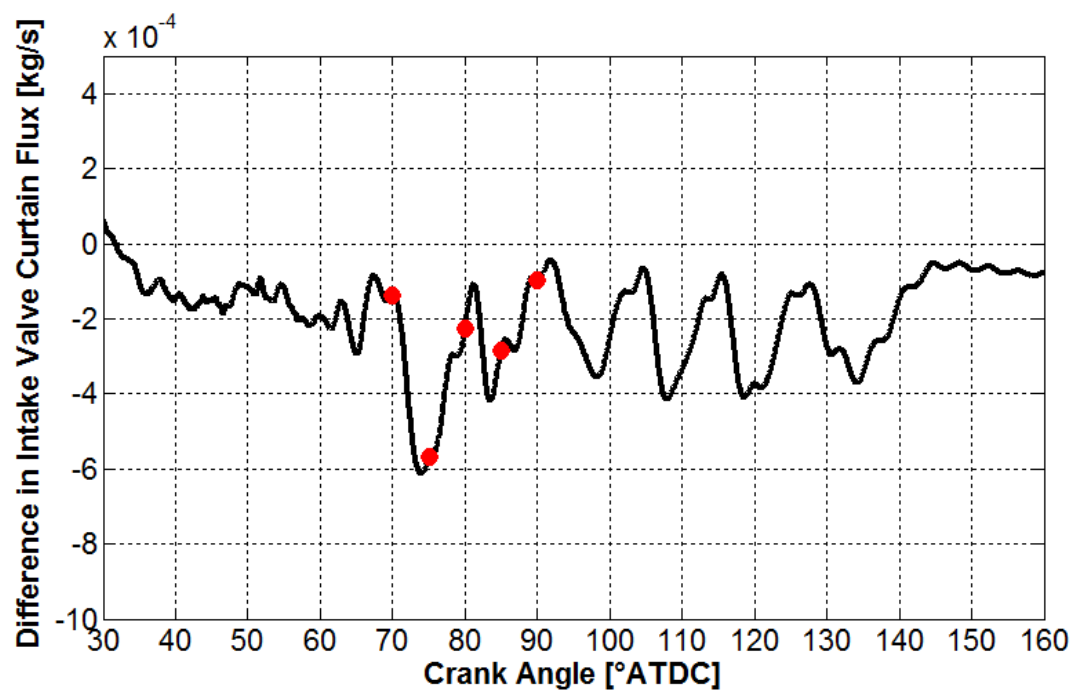

Figure 5 - Difference in valve curtain flux between the intake valves for cycle 10 with red markers used to highlight crank angles for images in Figure 6 


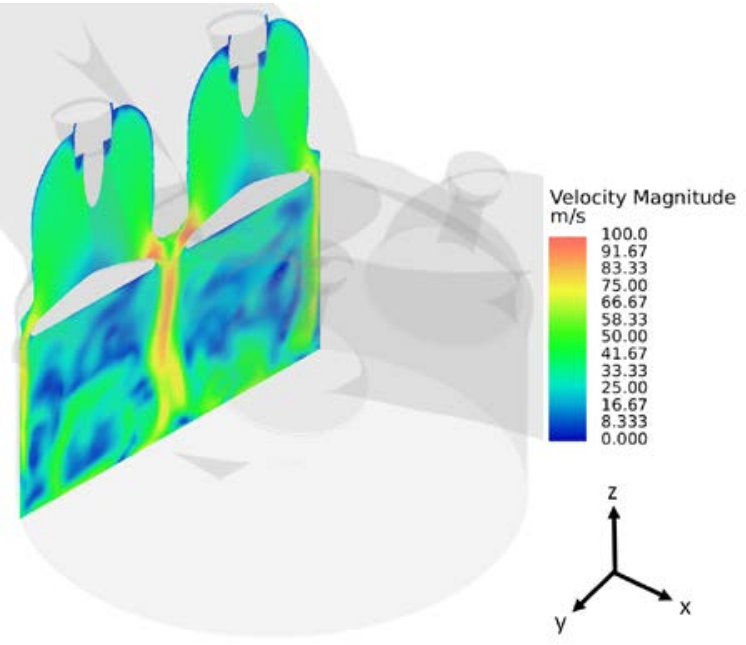

(a) $70^{\circ} \mathrm{ATDC}$

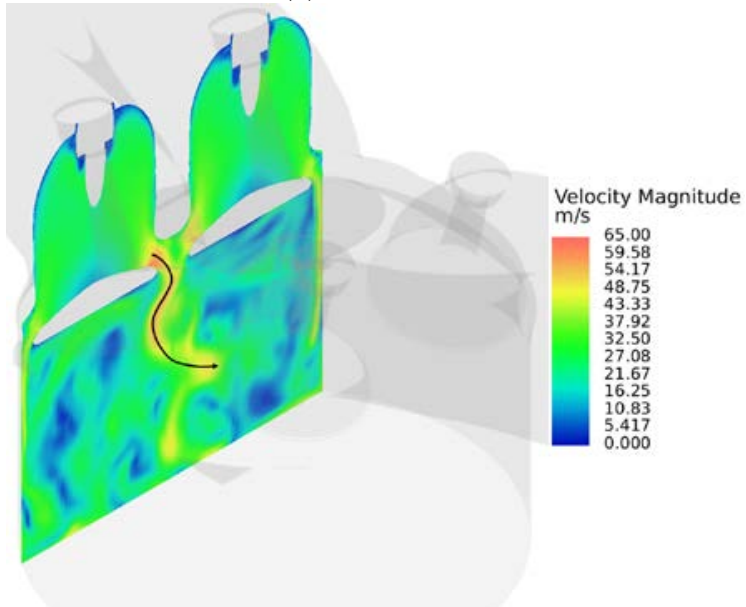

(c) $80^{\circ} \mathrm{ATDC}$

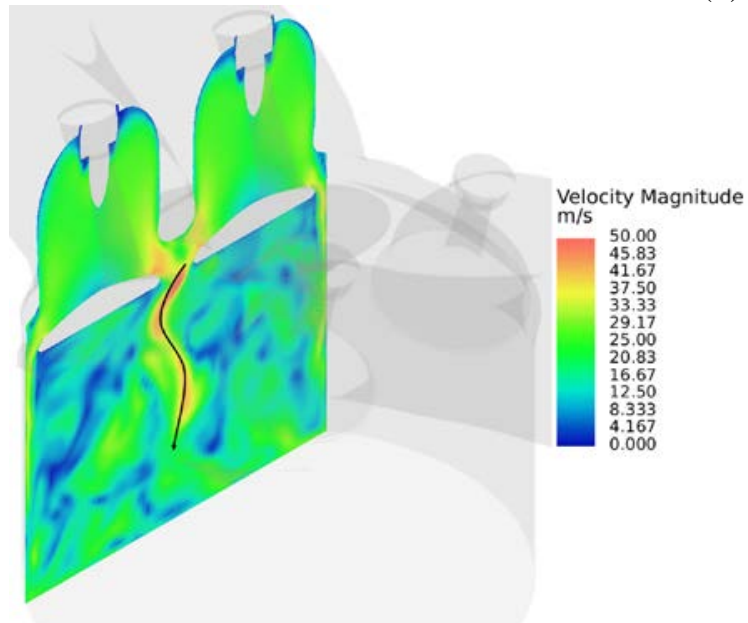

(e) $90^{\circ} \mathrm{ATDC}$

Figure 6 - Velocity magnitude contours for cycle 10 with black circles highlighting valve curtain flow imbalance and black arrows highlighting valve jet flapping
Velocity Magnitude

$\mathrm{m} / \mathrm{s}$
85.00
77.92
70.83

63.75
56.67
40.58

49.58
42.50
3.52

3.3 .42
28.33
2125

11.17
7.083
0.000

(b) $75^{\circ} \mathrm{ATDC}$

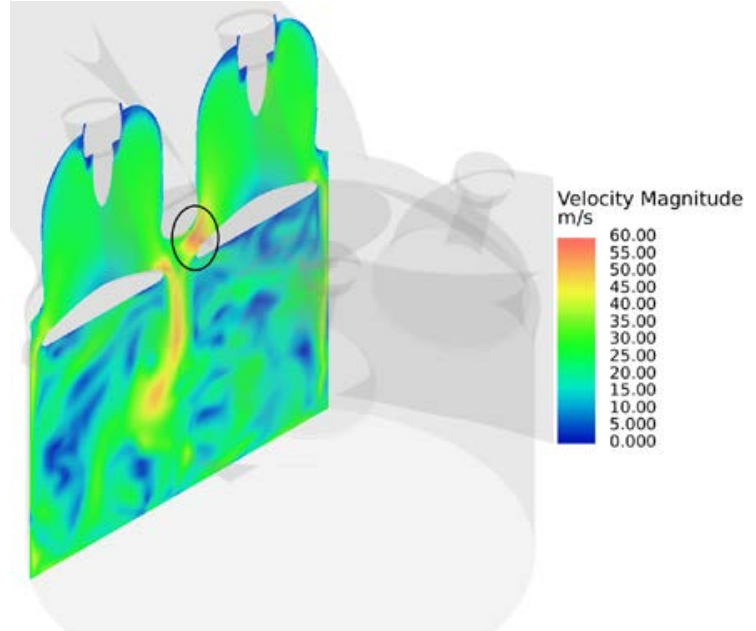

(d) $85^{\circ} \mathrm{ATDC}$ 
It has also been observed that all engine cycles show cycle-to-cycle variations in valve curtain flux through the intake stroke. As seen in Figure 7 where all engine cycles are overlaid, all cycles exhibit variation in the intake valve curtain flux with the magnitude and phasing of the variation changing on a cycle-by-cycle basis.

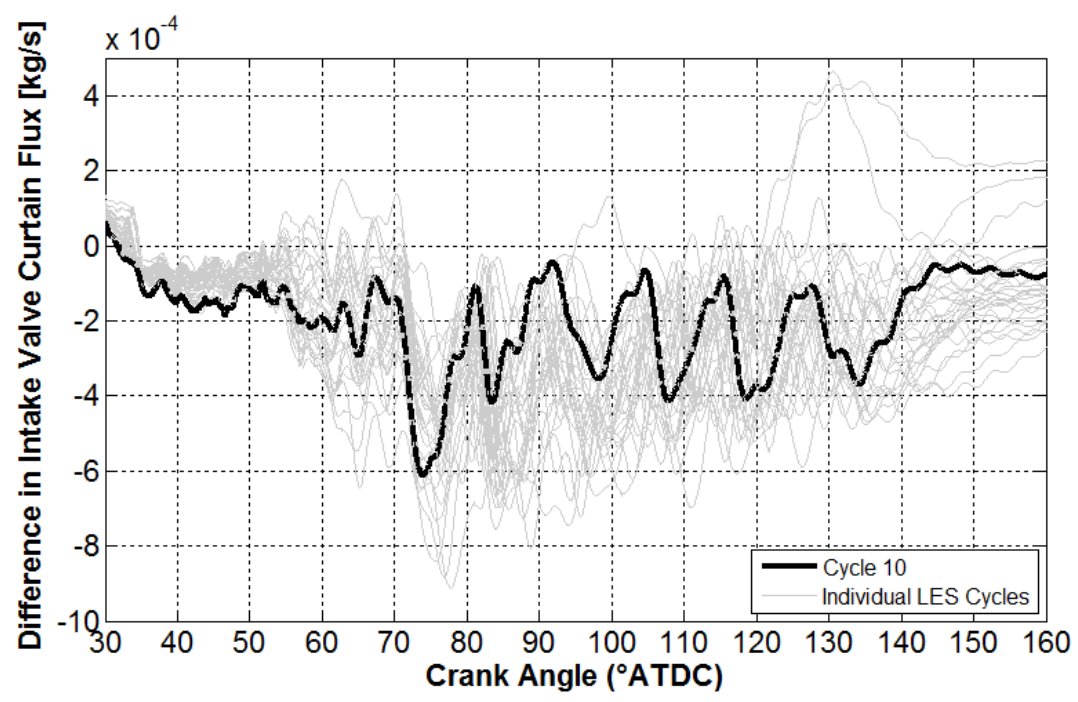

Figure 7 - Highlighting the variation in phase and magnitude of difference in intake valve curtain flux across all cycles

As an example of the cyclic variations present, Figure 8 shows the difference in intake valve curtain flux and velocity magnitude contours at $100^{\circ}$ ATDC for cycle 23 . Here the flapping intake valve jet can be seen to have lower penetration into combustion chamber but oscillate at a higher frequency when compared to cycle 10 . Figure 9 shows results at $75^{\circ}$ ATDC for cycle 12 where the flapping valve jet oscillates at a lower frequency but penetrates all the way to the piston crown surface. 


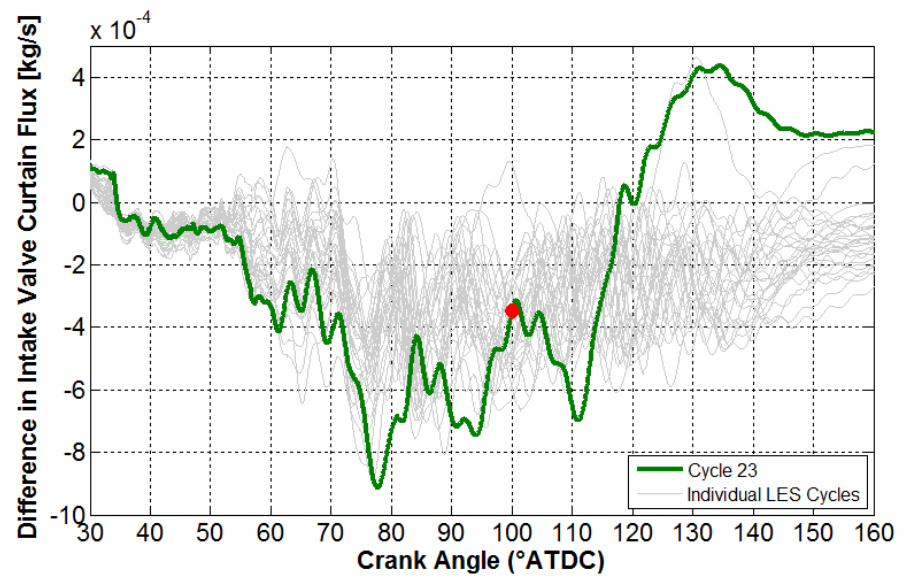

(a)

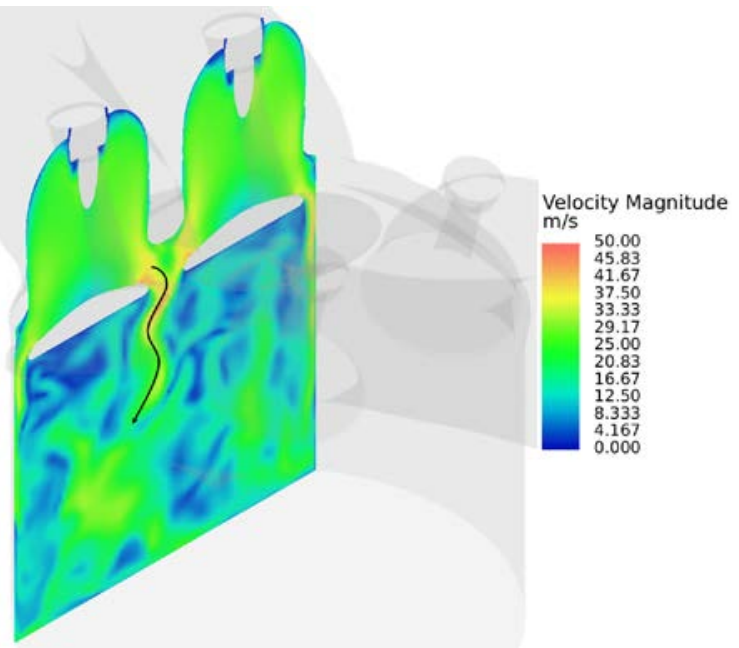

(b) $100^{\circ} \mathrm{ATDC}$

Figure 8 - Cycle 23 (a) Difference in intake valve curtain flux, (b) Velocity magnitude contours at $100^{\circ}$ ATDC

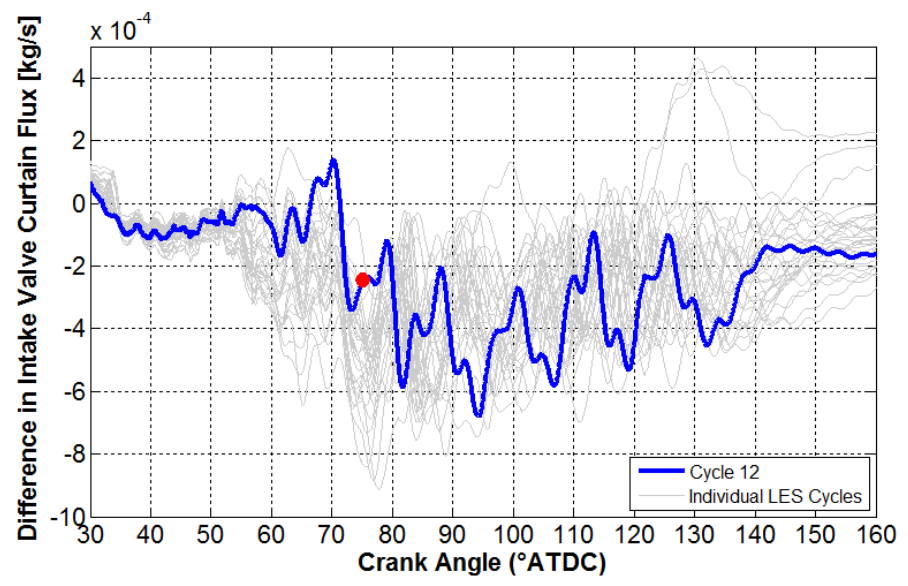

(a)

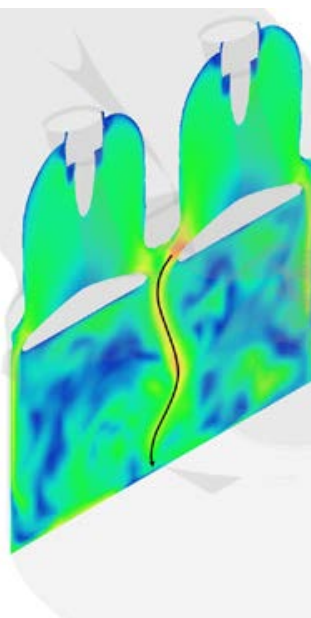

(b) $75^{\circ} \mathrm{ATDC}$

Figure 9 - Cycle 12 (a) Difference in intake valve curtain flux, (b) Velocity magnitude contours at $75^{\circ}$ ATDC

Due to variation in the magnitude and phase of the intake valve jet flapping that occurs on a cycle-by-cycle basis, when an ensemble-averaging process is applied to the velocity field, most of the information associated with jet flapping is lost and the results largely show a steady valve jet penetrating directly down into the combustion chamber, as shown by Figure 10(a). Interestingly, contrary to the findings of Hasse (2016), when compared to a RANS solution of the same geometry (using the RNG k- $\varepsilon$ turbulence model, Yakhot \& Orszag, (1986) and Yakhot, 
Orszag, Thangam, et al. (1992)) as shown in Figure 10 (b), jet flapping is visible but due to the time-averaging of the N-S equations, does not capture any of the cyclic-variability present in the LES predictions. This finding becomes clear when the difference in valve curtain mass flux is calculated for the LES ensemble-average and RANS results, shown in Figure 11. The averaging effect on the perturbation, and then on the resultant valve jet instability in the LES ensembleaverage trace is clear with a significant reduction in amplitude of the oscillatory trend. The difference in valve curtain flux for the RANS simulation shows a similar trend to that of the previously presented LES cycle 10 (Figure 5) and explains the presence of valve jet flapping in the predicted velocity field in the RANS predictions.

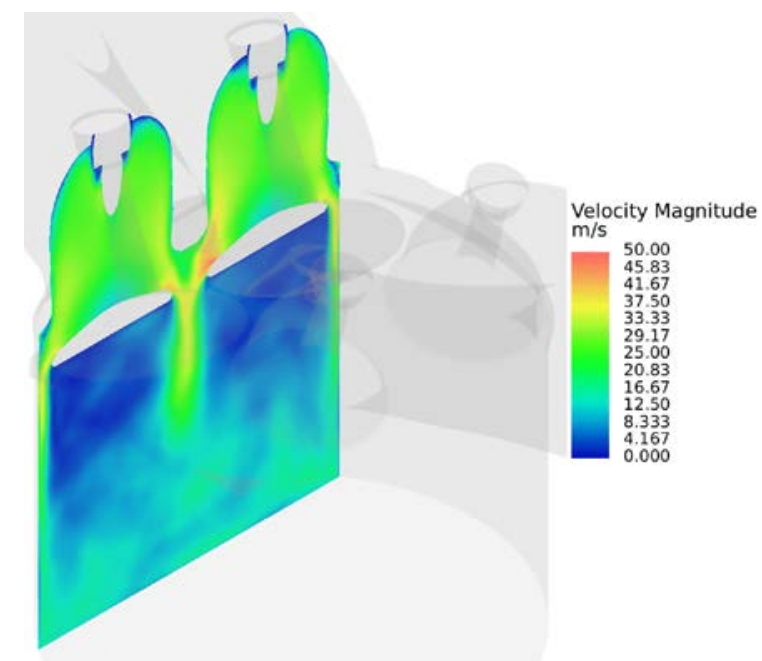

(a) LES Ensemble-Average

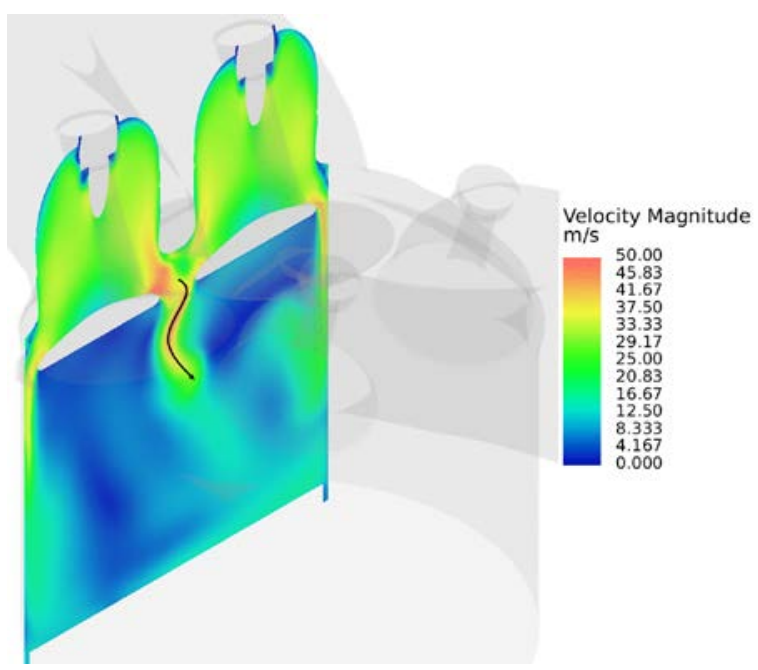

(b) RANS

Figure 10 - Comparison of velocity magnitude contours at $100^{\circ}$ ATDC for (a) LES 29 cycle ensemble-average, and (b) RANS predictions 


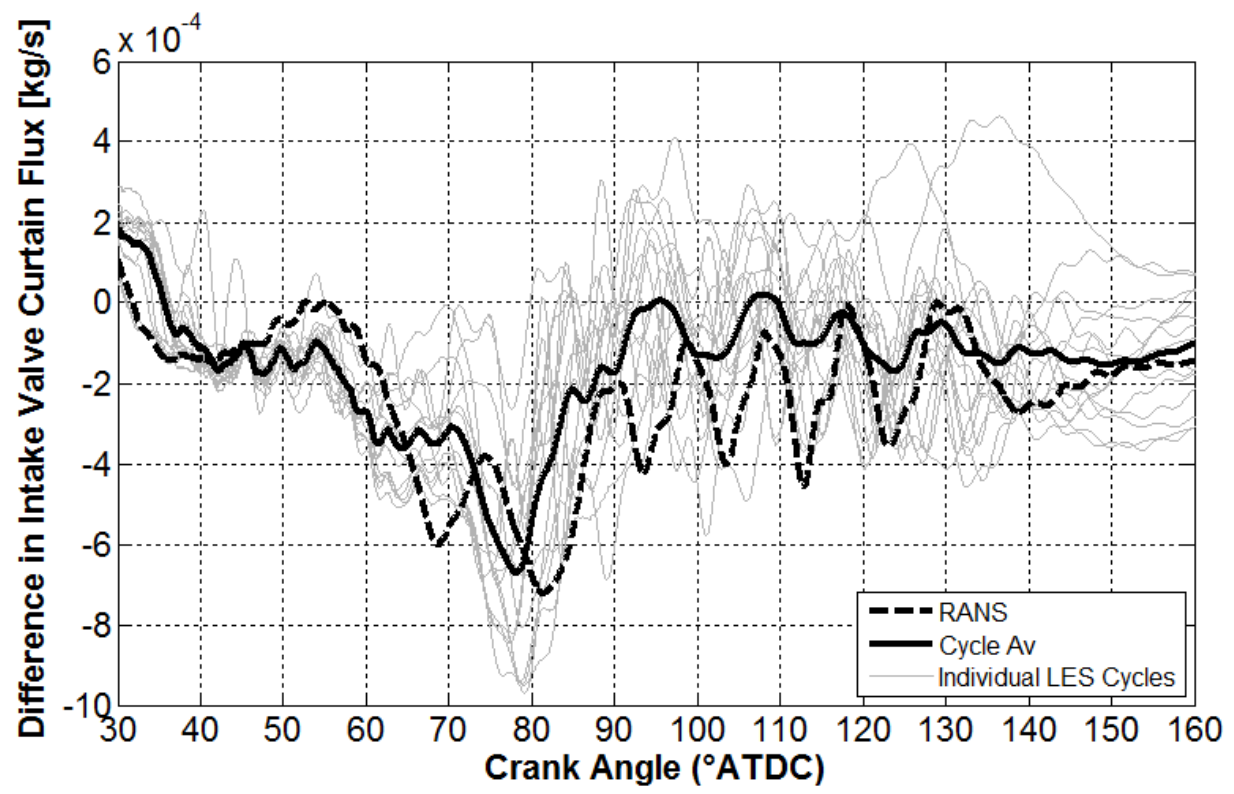

Figure 11 - Difference in valve curtain mass flux as a function of crank angle for the LES ensemble-average and for a RNG k- $\varepsilon$ turbulence model

\section{5-Conclusions}

Intake valve jet flapping within a GDI engine has been investigated using a detailed 3D-CFD model and LES turbulence modelling approach. Details of the experimental test case and computational setup have been provided and references provided detailing the validation of the numerical model to experimental results.

Intake valve jet flapping was seen to be the sinusoidal flow motion generated between the two intake valves during the intake stroke, as a consequence of turbulent fluctuations within the valve curtains.

An example of prominent intake valve jet flapping was presented and discussed, indicating the presence of valve curtain flux imbalance that stimulates the subsequent jet flapping event. Significant cyclic variability has been observed in both the magnitude and phasing of valve curtain imbalance resulting in variations in frequency and penetration of the resultant flapping flow structure. It has also been observed that the valve jet flapping phenomenon is mostly lost during the ensemble-averaging procedure typically used in LES studies. In a comparative RANS 
simulation, whilst valve jet flapping was observed, it does not capture the cyclic variability present in the LES predictions.

Due to its significant cyclic variability and impact on large scale flow structures within cylinder, valve jet flapping influences the in-cylinder mixing processes and the final turbulence levels at the point of spark ignition in GDI engines. Fifteen additional engine cycles have recently been completed including an early injection event using a Lagrangian discrete droplet model to allow investigation into the impact of variations in intake valve jet flapping on the atomisation process and distribution of the fuel vapour cloud on a cycle-by-cycle basis.

\section{Acknowledgements}

To be inserted post-review process

\section{References}

Angelberger, C., Poinsot, T. \& Delhay, B. (1997) Improving Near-Wall Combustion and Wall Heat Transfer Modeling in SI Engine Computations, SAE Technical Paper 972881.

Beavis, N.J., Ibrahim, S.S. \& Malalasekera, W. (2016) Numerical Simulations of a GDI Engine Flow Using LES and POD, SAE Technical Paper 2016-01-0598.

Beavis, N.J., Ibrahim, S.S., Manickam, P.K. \& Malalasekera, W. (2015) 'Characteristics of GDI Engine Flow Structures', 12th International Congress, Engine Combustion Processes, Current Problems and Modern Technologies, [online] https://dspace.lboro.ac.uk/2134/20016 (Accessed 20 April 2017).

Borée, J., Maurel, S. \& Bazile, R. (2002) 'Disruption of a compressed vortex', Physics of Fluids, Vol. 14 No. 7, pp.2543-2556.

Dugue, V., Gauchet, N. \& Veynante, D. (2006) Applicability of Large Eddy Simulation to the Fluid Mechanics in a Real Engine Configuration by Means of an Industrial Code, SAE Technical Paper 2006-01-1194.

Fontanesi, S., Paltrinieri, S. \& D’Adamo, A. (2013) Analysis of cyclic variability in a turbocharged GDI engine using LES. imem.cray.com, [online] https://imem.cray.com/2013/Meeting-2013/6-Emilia-Fontanesi-cyclic-LES.pdf (Accessed 20 April 2017).

Genzale, C.L., Reitz, R.D. \& Musculus, M.P.B. (2009) 'Optical Diagnostics and MultiDimensional Modeling of Spray Targeting Effects in Late-Injection Low-Temperature Diesel Combustion', SAE Int. J. Engines, Vol. 2 No. 2, pp.150-172. 
Gosman, A.D., Tsui, Y.Y. \& Watkins, A.P. (1984) Calculation of Three Dimensional Air Motion in Model Engines, SAE Technical Paper 840229.

Hasse, C. (2016) 'Scale-resolving simulations in engine combustion process design based on a systematic approach for model development', International Journal of Engine Research, Vol. 17 No. 1, pp.44-62.

Hasse, C., Sohm, V. \& Durst, B. (2009) 'Detached eddy simulation of cyclic large scale fluctuations in a simplified engine setup', International Journal of Heat and Fluid Flow, Vol. 30 No. 1, pp.32-43.

Jarvis, S., Justham, T., Clarke, A., Garner, C.P., et al. (2006) Motored SI IC Engine In-Cylinder Flow Field Measurement Using Time Resolved Digital PIV for Characterisation of Cyclic Variation, SAE Technical Paper 2006-01-1044.

Justham, T., Jarvis, S., Garner, C.P., Hargrave, G.K., et al. (2006) Single Cylinder Motored SI IC Engine Intake Runner Flow Measurement Using Time Resolved Digital Particle Image Velocimetry, SAE Technical Paper 2006-01-1043.

Launder, B.E. \& Spalding, D.B. (1974) 'The Numerical Computation of Turbulent Flows', Comput. Methods Appl. Mech. Eng., Vol. 3, pp.269-289.

Lavoie, G.A., Heywood, J.B. \& Keck, J.C. (1970) 'Experimental and Theoretical Study of Nitric Oxide Formation in Internal Combustion Engines', Combustion Science and Technology, Vol. 1, pp.313-326.

Poinsot, T. (1996) 'Using Direct Numerical Simulations to Understand Premixed Turbulent Combustion', Twenty-Sixth International Symposium on Combustion/The Combustion Institute, pp.219-232.

Rutland, C.J. (2011) 'Large-eddy simulations for internal combustion engines - a review', International Journal of Engine Research, Vol. 12 No. 5, pp.421-451.

Serras-pereira, J., Aleiferis, P., Richardson, D. \& Wallace, S. (2007) Spray Development in a Direct-Injection Spark-Ignition Engine, SAE Technical Paper 2007-01-2712.

Smagorinsky, J. (1963) 'General circulation experiments with the primitive equations. I. The basic experiment', Mon. Weather Rev, Vol. 91 No. 3, pp.99-164.

St Hill, N., Asadamongkon, P., Lee, K.C. \& Yianneskis, M. (2000) 'A study of turbulence and cyclic variation levels in internal combustion engine cylinders', Proceedings of the 10th International Symposium on Applications of Laser Techniques to Fluid Mechanics.

Yakhot, V. \& Orszag, S.A. (1986) 'Renormalization group analysis of turbulence. I. Basic theory', Journal of Scientific Computing, Vol. 1 No. 1, pp.3-51.

Yakhot, V., Orszag, S.A., Thangam, S., Gatski, T.B., et al. (1992) 'Development of turbulence models for shear flows by a double expansion technique', Physics of Fluids A: Fluid Dynamics, Vol. 4 No. 7, pp.1510-1520.

\section{Nomenclature}

$C_{S} \quad$ Smagorinsky constant 


\section{$S$ Strain rate tensor}

$t$ Time

$\overline{u_{\imath}} \quad$ Mean or filtered velocity component

$u_{i}$ Instantaneous velocity component

$u_{i}^{\prime} \quad$ Fluctuating or SGS velocity component

$V$ Cell volume

$\Gamma_{i j} \quad$ Viscous stress tensor

$\Delta$ Filter width

$\rho$ Density

$\tau_{i j} \quad$ Sub-grid scale stresses

$v_{T} \quad$ Turbulence viscosity

\section{Abbreviations}

3D-CFD

Three Dimensional Computational Fluid Dynamics

ATDC After Top Dead Centre

BDC Bottom Dead Centre

CA Crank Angle

CD Central Differencing

CFL Courant-Friedrichs-Lewy

GDI Gasoline Direct Injection 
HSPIV High Speed Particle Image Velocimetry

ICE Internal Combustion Engine

LES Large Eddy Simulation

MARS Monotone Advection and Reconstruction

N-S Navier-Stokes

RANS Reynolds-Averaged Navier-Stokes

SGS Sub-Grid Scale 